\title{
PENERAPAN METODE PARTISIPATORIK DALAM MENINGKATKAN HASIL BELAJAR BAHASA INDONESIA SISWA KELAS XI SMA NEGERI 19 MAKASSAR
}

\author{
Anin Asnidar ${ }^{1}$ Sumarni $W^{2}$ \\ Pendidikan Bahasa dan Sastra Indonesia, Universitas Muhammadiyah Makassar \\ anin.asnidar@gmail.com \\ Pendidikan Bahasa dan Sastra Indonesia, Universitas Muhammadiyah Makassar \\ sumarni@gmail.co.id
}

\begin{abstract}
This study was a class act that aims to improve learning outcomes Indonesian students of class XI. SMA Negeri 19 Makassar through the application of participatory methods. This research conducted action research (classroom action research) in addition, this study also planned to be conducted in two cycles, each cycle through four stages: 1) Planning 2) Actions 3) Observation 4) Reflection. Collecting data by using test results of study and observation. The collected data were analyzed quantitatively and qualitatively. The results showed that the application of participatory methods to improve learning outcomes Indonesian students of class XI SMA Negeri19 Makassar. The improved learning outcomes looks at the implementation of the action in the first cycle that students who are in the category completed by 11 students with $44 \%$ while the percentage of students in a category is not exhaustive as many as 14 students with a percentage of $56 \%$ with an average value of 64.68. And the second cycle which showed an increase in student learning outcomes. that students who are in the category completed by 25 students with a percentage of $100 \%$, while the students are in the category of not completed as much as 0 students with a percentage of $0 \%$ with an average value 82,64.Based on research results suggested that 1) a teacher of language and literature Indonesia, especially Indonesian teacher at SMA Negeri 19 Makassar to apply participatory learning methods as a method of improving the learning outcomes Indonesian. 2) students should be more actively involved in the learning process in the classroom so as to have the confidence and more eager to learn.
\end{abstract}

Keywords. Improve learning outcomes Indonesian, participatory method

\begin{abstract}
Abstrak
Penelitian ini adalah tindakan kelas yang bertujuan untuk meningkatkan hasil belajar bahasa Indonesia siswa kelas XI. SMA. Negeri 19 Makassar. Melalui penerapan metode partisipatorik. Penelitian ini dilaksanakan dengan penelitian tindakan kelas (classroom action research) selain itu penelitian ini juga direncanakan akan dilaksanakan dalam dua siklus, setiap siklus melalui empat tahap yaitu 1) Perencanaan 2) Tindakan 3) Observasi 4) Refleksi. Pengambilan data dengan menggunakan tes hasil belajar dan observasi. Data yang terkumpul kemudian dianalisis secara kuantitatif dan kualitatif. Hasil penelitian menunjukkan bahwa penerapan metode partisipatorik dapat meningkatkan hasil belajar bahasa Indonesia siswa kelas XI Sma. Negeri 19 Makassar. Peningkatan hasil belajar tampak pada pelaksanaan tindakan dalam siklus I bahwa siswa yang berada pada kategori tuntas sebanyak 11 siswa dengan persentase $44 \%$ sedangkan siswa yang berada pada
\end{abstract}


kategori tidak tuntas sebanyak 14 siswa dengan persentase $56 \%$ dengan nilai rata-rata 64,68. Dan siklus II yang memperlihatkan adanya peningkatan hasil belajar siswa. bahwa siswa yang berada pada kategori tuntas sebanyak 25 siswa dengan persentase $100 \%$, sedangkan siswa yang berada pada kategori tidak tuntas sebanyak 0 siswa dengan persentase $0 \%$ dengan nilai rata-rata 82,64.Berdasarkan hasil penelitian disarankan agar 1) guru bahasa dan sastra Indonesia, khususnya guru Bahasa Indonesia Sma. Negeri 19 Makassar untuk menerapkan metode pembelajaran partisipatorik sebagai salah satu metode meningkatkan hasil belajar bahasa Indonesia. 2) siswa hendaknya lebih berperan aktif dalam proses belajar di kelas sehingga mempunyai rasa percaya diri dan lebih bersemangat untuk belajar.

\section{Kata kunci. Meningkatkan hasil belajar bahasa Indonesia, Metode partisipatorik}

\section{Pendahuluan}

Hasil belajar siswa sangat dipengaruhi oleh kualitas pembelajaran yang dilaksanakan di sekolah. Dan salah satu yang menentukan kualitas pembelajaran adalah penggunaan metode pembelajaran yang tepat dengan materi yang diajarkan. Mackey (dalam Djumingin, 2007: 66), mengemukakan bahwa metode pembelajaran bahasa terdiri dari lima belas. Metode pembelajaran bahasa tersebut adalah metode langsung, metode alamiah (natural method), metode psykologi, metode fonetik, metode tata bahasa, metode terjemahan, metode terjemahan tata bahasa, metode membaca, metode ekletik, metode unit, metode language control, metode mimicry atau metode menghafal, metode teori praktek, metode gognate, dan metode dual language. Namun pada kenyataannya, berdasarkan pengalaman penulis dan beberapa mahasiswa yang melaksanakan Program Latihan Profesi, masih banyak sekolah yang kurang memperhatikan penggunaan metode pembelajaran dalam setiap penampilan mengajar.

Pembelajaran biasanya hanya disampaikan secara konvensional, dimana guru yang berperan aktif dan siswa yang cenderung pasif. Siswa yang cepat menguasai materi pelajaran kurang bisa berbagi dengan temannya yang sulit menerima materi pelajaran, sehingga sulit terjadi kerjasama dalam hal berbagi ilmu pengetahuan. Hal ini sangat berpengaruh terhadap prestasi belajar di sekolah. Oleh karena itu, diperlukan inovasi dalam kegiatan pembelajaran untuk mengatasi permasalahan tersebut. Maka dengan memperhatikan berbagai konsep dan teori belajar dikembangkanlah suatu metode pembelajaran yang disebut dengan metode Partisipatorik.

Menurut Sujana (2000: 154), metode partisipatorik dapat diartikan sebagai upaya pendidik untuk mengikutsertakan peserta didik dalam kegiatan pembelajaran. Kegiatan pembelajaran dengan penerapan metode partisipatorik mengandung arti ikut sertanya peserta didik dalam program pembelajaran. Keikutsertaan peserta didik itu diwujudkan dalam tiga tahapan kegiatan pembelajaran yaitu perencanaan program (program planning), pelaksanaan (program implementation), dan penilaian (program evaluation) kegiatan pembelajaran.

Partisipasi peserta didik dalam tiga tahapan kegiatan itu pada hakekatnya merupakan kegiatan pembelajaran dalam makna yang wajar dan mempunyai pengaruh positif bagi peserta didik. Pengaruh partisipasi ini diharapkan akan dirasakan oleh peserta didik terutama setelah mereka mengikuti program kegiatan pembelajaran. Penerapan metode partisipatorik diarahkan supaya peserta 
didik diharapkan melibatkan diri dalam ketiga tahapan pembelajaran itu.

Pemenggalan partisipasi peserta didik hanya dalam satu tahapan pembelajaran adalah metode yang menyimpang dari metode partisipatorik itu sendiri. Sebagai alasan dari penyimpangan tersebut karena metode partisipatorik menuntut terjadinya keikutsertaan peserta didik dalam pembelajaran. Realitas keikutsertaan itu dibuktikan dengan keaktifan peserta didik dalam perencanaan, pelaksanaan, dan penilaian program pembelajaran. Dengan demikian, partisipasi peserta didik pada ketiga tahapan tersebut sangat diperlukan dalam penerapan metode partisipatorik dalam pembelajaran di kelas.

Sekolah merupakan salah satu sarana yang sangat penting dalam memberikan pembinaan dan pengajaran kepada siswa. Umumnya, anak didik memperoleh pengetahuan, kecakapan dan pengembangan keperibadian di sekolah. Sejalan dengan itu, tujuan pengajaran bahasa adalah membantu anak didik mengembangkan kemampuan berkomunikasi, baik secara lisan maupun secara tertulis.

Tujuan pengajaran berbahasa memuat tiga komponen, yaitu: kebahasaan, pemahaman dan penggunaan. Dalam komponen kebahasaan tercakup pengetahuan tentang tanda baca, tata bunyi, tata bahasa, semantik dan pengetahuan sastra dalam komponen pemahaman tercakup keterampilan mendengar dan membaca serta komponen penggunaan tercakup keterampilan berbicara dan menulis. Ketiga komponen pengajaran bahasa tersebut hendaknya dikuasai oleh siswa pada semua jenjang pendidikan agar mereka mampu berbahasa Indonesia yang baik dan benar ( Arifin \& Hadi, 1991:23 ).

Penggunaan bahasa Indonesia yang meliputi keterampilan berbicara, menyimak, membaca dan menulis harus betul-betul dikuasai oleh seorang siswa. Agar siswa dapat memahami, menguasai, dan menggunakan bahasa Indonesia yang baik dan benar, mereka harus mendapat pengetahuan yang sesuai dengan kebutuhan berdasarkan jenjang pendidikan tempat mereka menimba ilmu.

Berdasarkan ketentuan Kriteria

Ketuntasan Minimal (KKM) di SMA Negeri 19 Makassar yaitu 75, maka siswa dikatakan tuntas belajar jika skor rata-rata yang diperoleh minimal $75 \%$ dari skor ideal dan tuntas secara klasikal bila minimal $85 \%$ dari jumlah siswa telah lulus tuntas belajar secara perorangan.

Hasil observasi di SMA Negeri 19 Makassar menemukan hasil belajar Bahasa Indonesia masih rendah disebabkan karena empat faktor penting yaitu: (1) Siswa merasa jenuh dan bosan dengan pelajaran bahasa Indonesia karena selama pembelajaran hanya guru yang berperan aktif, (2) Proses dan metode pembelajaran yang diberikan oleh guru tidak bervariasi sehingga siswa tidak bergairah belajar, (3) Kurangnya kreatifitas guru dalam pembelajaran bahasa Indonesia, (4) Pembelajaran bahasa Indonesia hanya disampaikan secara konvensional di mana guru yang berperan aktif dan siswa yang cenderung pasif.

Bertitik tolak pada kenyataan di atas, maka penulis melakukan penelitian yang berjudul " Penerapan Metode Partisipatorik Dalam Meningkatkan Hasil Belajar Bahasa Indonesia Siswa Kelas XI SMA Negeri 19 Makassar. Penelitian ini, dilakukan dengan maksud untuk meningkatkan hasil belajar siswa kelas XI SMA Negeri 19 Makassar. Dalam menggunakan metode pembelajaran partisipatorik sekaligus untuk mengetahui sejauh mana konsep pengajaran bahasa yang diterapkan di sekolah tersebut, dan perbandingan hasil belajar Bahasa Indonesia siswa yang hasilnya baik dengan yang masih kurang 
baik di kelas XI SMA Negeri 19 Makassar yaitu $40 \%$ berbanding $60 \%$.

\section{Metode Penelitian}

Menurut Purwadarminta (1976), metode adalah cara yang telah teratur dan terpikir baik-baik untuk mencapai suatu maksud. The American Heritage Dictionary mengemukakan bahwa metode adalah " a means or manner of procedure; specially, a reguler and systematic way of accomplishing anything ... Method emphasizes procedures according to a detailed, logically ordered plan" (Morris, 1976: 826). Menurut Kamus Besar Bahasa Indonesia (KBBI), metode adalah cara kerja yang bersistem untuk memudahkan pelaksanaan suatu kegiatan guna mencapai tujuan yang ditemukan (Moeliono, dkk, 1990: 580-581).

Metode yang digunakan dalam penelitian ini adalah metode partisipatorik yaitu metode yang digunakan dalam pembelajaran partisipatif. Pertama, metode pembelajaran perseorangan (individual methodsi) yang terdiri atas tutorial, bimbingan perorangan, pembelajaran individual, dan magang. Kedua, metode pembelajaran kelompok (group methods) yang terdiri atas diskusi, demonstrasi, kerja kelompok, eksperimen, pemecahan masalah, ceramah bervariasi, simulasi. Ketiga, metode pembelajaran massal atau pembangunan masyarakat (community methods) yang terdiri atas aksi partisipasi, demonstrasi proses, dan demonstrasi hasil.

Ketiga metode dalam pembelajaran partisipatif yang telah diuraikan di atas, metode pembelajaran kelompok dipandang lebih tepat digunakan dalam pembelajaran partisipatif. Di sini guru memotivasi dan melibatkan siswa dalam merencanakan, melaksanakan, dan menilai kegiatan pembelajaran. Pelibatan siswa ini memberi makna bahwa kegiatan pembelajaran dilakukan bersama dalam kelompok sehingga proses pembelajaran partisipatif mensyaratkan dukungan metode pembelajaran kelompok (Sudjana, 2005: 2).

\section{Hasil Penelitian}

Hasil penelitian tindakan kelas am penerapan metode partisipatorik am meningkatkan hasil belajar bahasa Indonesia siswa kelas XI IPA -1 SMA Negeri 19 Makassar dilaksanakan dalam dua siklus. Adapun uraian kegiatan siklus I dan siklus II sebagai berikut:

\section{1) Hasil Penelitian Siklus I}

\begin{tabular}{|c|c|c|c|c|c|c|c|}
\hline \multirow{2}{*}{ No. } & \multirow{2}{*}{ Komponen yang Diamati } & \multicolumn{4}{|c|}{ Siklus I } & \multirow{2}{*}{$\begin{array}{l}\text { Rata- } \\
\text { Rata }\end{array}$} & \multirow{2}{*}{$\begin{array}{l}\text { Persentase } \\
\quad(\%)\end{array}$} \\
\hline & & I & II & III & IV & & \\
\hline 1. & $\begin{array}{l}\text { Siswa yang hadir pada saat proses } \\
\text { pembelajaran berlangsung. }\end{array}$ & 23 & 24 & 24 & \multirow{4}{*}{$\begin{array}{c}\text { TES } \\
\text { S } \\
\text { I } \\
\text { K } \\
\text { L } \\
\text { U } \\
\text { S } \\
1\end{array}$} & 23,6 & 94,6 \\
\hline 2. & $\begin{array}{l}\text { Siswa yang mendengarkan atau } \\
\text { memperhatikan penjelasan guru } \\
\text { pada saat proses pembelajaran } \\
\text { berlangsung. }\end{array}$ & 19 & 21 & 21 & & 20,3 & 81,3 \\
\hline 3. & $\begin{array}{l}\text { Siswa mengajukan pertanyaan } \\
\text { kepada guru pada saat proses } \\
\text { pembelajaran berlangsung. }\end{array}$ & 9 & 10 & 15 & & 11,3 & 45,3 \\
\hline 4. & $\begin{array}{l}\text { Siswa menjawab pertanyaan, baik } \\
\text { dari guru maupun siswa lain pada }\end{array}$ & 10 & 10 & 14 & & 11,3 & 45,3 \\
\hline
\end{tabular}




\begin{tabular}{|c|l|c|c|c|c|c|c|}
\hline & $\begin{array}{l}\text { saat proses pembelajaran } \\
\text { berlangsung. }\end{array}$ & & & & & & \\
\hline 5. & $\begin{array}{l}\text { Siswa aktif mengerjakan tugas } \\
\text { harian. }\end{array}$ & 18 & 18 & 20 & & 18,6 & 74,6 \\
\cline { 6 - 8 }
\end{tabular}

Dari tabel 7 dijelaskan bahwa siswa yang hadir pada saat proses pembelajaran berlangsung rata-rata23,6, siswa yang mendengarkan atau memperhatikan penjelasan guru pada saat proses pembelajaran berlangsung rata-rata 20,4, siswa mengajukan pertanyaan

Tabel 4.2 Statistik Skor penerapan metode partisipatorik dalam meningkatkan hasil belajar bahasa Indonesia pada Siklus I

\begin{tabular}{|c|c|}
\hline Statistik & Nilai \\
\hline Subjek & 25 \\
\hline Skor Ideal & 100 \\
\hline Skor Maksimum & 80 \\
\hline Skor Minimum & 50 \\
\hline Rentang Skor & 30 \\
\hline Skor Rata-Rata & 64,48 \\
\hline
\end{tabular}

Berdasarkan tabel 4.2 di atas bahwa subjek yang diteliti adalah 25, skor ideal yang diharapkan adalah 100 , skor maksimum yang dicapai adalah 80 , skor minimum yang dicapai adalah 50 , rentang skornya adalah 30 , skor rata-rata yang telah dicapai adalah 64,48

Tabel 4.3 Distribusi Frekuensi dan Persentase Skor penerapan metode partisipatorik dalam meningkatkan hasil belajar bahasa Indonesia pada Siklus I

\begin{tabular}{|c|c|c|c|}
\hline Skor & Kategori & Frekuensi & Persentase (\%) \\
\hline $0-60$ & Sangat rendah & 9 & 36 \\
$61-70$ & Rendah & 11 & 44 \\
$71-80$ & Sedang & 5 & 20 \\
$81-90$ & Tinggi & 0 & 0 \\
$91-100$ & Sangat tinggi & 0 & 0 \\
\hline \multicolumn{2}{|c|}{ Jumlah } & 25 & 100 \\
\hline
\end{tabular}

Berdasarkan tabel 4.3, di atas dapat dinyatakan bahwa dari 25 siswa yang menjadi subjek penelitian, 9 siswa yang berada pada kategori sangat rendah, 11 siswa yang berada pada kategori rendah, 5 siswa yang berada pada kategori sedang, 0 siswa yang berada pada kategori
Apabila skor hasil belajar siswa dikelompokkan ke dalam lima kategori maka diperoleh distribusi frekuensi skor yang dapat ditunjukkan pada tabel 8 di bawah ini: kepada guru pada saat proses pembelajaran berlangsung rata-rata 11,3, siswa menjawab pertanyaan, baik dari proses pembelajaran berlangsung rata-rata 11,3 , siswa yang mengerjakan tugas harian rata-rata18,6.

tinggi dan 0 siswa yang berada pada kategori sangat tinggi.

Apabila hasil belajar pada Siklus I dianalisis, maka persentase ketuntasan belajar siswa pada siklus I dapat dilihat pada Tabel 4.4 berikut: 
Tabel 4.4 Deskripsi Ketuntasan Belajar Siswa Kelas XI SMA Negeri 19Makassar pada Siklus I

\begin{tabular}{|c|c|c|c|}
\hline Skor & Kategori & Frekuensi & Persentase (\%) \\
\hline $0-64$ & Tidak tuntas & 14 & 56 \\
$65-100$ & Tuntas & 11 & 44 \\
\hline \multicolumn{2}{|c|}{ Jumlah } & 25 & 100 \\
\hline
\end{tabular}

Berdasarkan tabel 4.4 di atas bahwa siswa yang berada pada kategori tuntas sebanyak 11 siswa dengan persentase $44 \%$ sedangkan siswa yang berada pada kategori tidak tuntas sebanyak 14 siswa dengan persentase $56 \%$.

Berdasarkan hasil analisis kategori skor dipadukan dengan hasil observasi

dan diskusi dengan guru. Peneliti menarik kesimpulan sementara tentang pelaksanaan siklus I bahwa penerapan metode partisipatorik dalam meningkatkan hasil belajar bahasa Indonesia siswa kelas XI IPA-1 masih perlu ditingkatkan lagi, jadi masih perlu diadakan pengulangan proses pembelajaran baik itu peningkatan keterampilan siswa dalam menentukan pokok-pokok isi pembacaan sambutan/khotbah dan wawancara maupun cara peningkatan materi kepada siswa. Hasil yang diperoleh masih harus ditingkatkan sesuai dengan ketuntasan pencapaian hasil memahami pembacaan cerpen yang diharapkan.

\section{Hasil Penelitian Siklus II}

Tabel4.5. Hasil Observasi Kegiatan Belajar Siswa pada Siklus II

\begin{tabular}{|c|c|c|c|c|c|c|c|}
\hline \multirow[t]{2}{*}{ No. } & \multirow[t]{2}{*}{ Komponen yang Diamati } & \multicolumn{4}{|c|}{ Siklus II } & \multirow{2}{*}{$\begin{array}{l}\text { Rata- } \\
\text { Rata }\end{array}$} & \multirow{2}{*}{$\begin{array}{l}\text { Persentase } \\
\quad(\%)\end{array}$} \\
\hline & & I & II & III & IV & & \\
\hline 1. & $\begin{array}{l}\text { Siswa yang hadir pada saat proses } \\
\text { pembelajaran berlangsung. }\end{array}$ & 25 & 25 & 25 & \multirow{5}{*}{$\begin{array}{c}\text { TES } \\
\text { S } \\
\text { I } \\
\text { K } \\
\text { L } \\
\text { U } \\
\text { S } \\
2\end{array}$} & 25 & 100 \\
\hline 2. & $\begin{array}{l}\text { Siswa yang mendengarkan atau } \\
\text { memperhatikan penjelasan guru } \\
\text { pada saat proses pembelajaran } \\
\text { berlangsung. }\end{array}$ & 22 & 24 & 25 & & 22 & 86,7 \\
\hline 3. & $\begin{array}{l}\text { Siswa mengajukan pertanyaan } \\
\text { kepada guru pada saat proses } \\
\text { pembelajaran berlangsung. }\end{array}$ & 19 & 25 & 25 & & 24 & 90 \\
\hline 4. & $\begin{array}{l}\text { Siswa menjawab pertanyaan, baik } \\
\text { dari guru maupun siswa lain pada } \\
\text { saat proses pembelajaran } \\
\text { berlangsung. }\end{array}$ & 23 & 24 & 25 & & 23 & 89 \\
\hline 5. & $\begin{array}{l}\text { Siswa aktif mengerjakan tugas } \\
\text { harian. }\end{array}$ & 22 & 23 & 25 & & 24 & 97,5 \\
\hline
\end{tabular}

Dari tabel 4.5 dijelaskan bahwa siswa yang hadir pada saat proses

pembelajaran berlangsung rata-rata 25 , siswa yang mendengarkan atau 
memperhatikan penjelasan guru pada saat proses pembelajaran berlangsung rata-rata 22, siswa mengajukan pertanyaan kepada guru pada saat proses pembelajaran berlangsung rata-rata 18 , siswa menjawab

Tabel 4.6 Statistik Skor penerapan metode partisipatorik dalam meningkatkan hasil belajar bahasa Indonesia pada Siklus I

\begin{tabular}{|c|c|}
\hline Statistik & Nilai \\
\hline Subjek & 25 \\
\hline Skor Ideal & 100 \\
\hline Skor Maksimum & 95 \\
\hline Skor Minimum & 75 \\
\hline Rentang Skor & 20 \\
\hline Skor Rata-Rata & 82,88 \\
\hline
\end{tabular}

Berdasarkan tabel 4.6 di atas bahwa subjek yang diteliti adalah 25, skor ideal yang diharapkan adalah 100, skor maksimum yang dicapai adalah 95, skor minimum yang dicapai adalah 75 , rentang skornya adalah 20 , skor rata-rata yang telah dicapai adalah 82,88.

Apabila skor hasil belajar siswa dikelompokkan ke dalam lima kategori

\begin{tabular}{|c|c|c|c|}
\hline Skor & Kategori & Frekuensi & Persentase (\%) \\
\hline $0-60$ & Sangat rendah & 0 & 0 \\
$61-70$ & Rendah & 0 & 0 \\
$71-80$ & Sedang & 11 & 56 \\
$81-90$ & Tinggi & 7 & 28 \\
$91-100$ & Sangat tinggi & 4 & 16 \\
\hline \multicolumn{2}{|c|}{ Jumlah } & 25 & 100 \\
\hline
\end{tabular}

berdasarkan tabel 4.7, di atas dapat dinyatakan bahwa dari 25 siswa yang menjadi subjek penelitian, 0 siswa yang berada pada kategori sangat rendah, 0 siswa yang berada pada kategori rendah, 11 siswa yang berada pada kategori sedang, 7 siswa yang berada pada kategori

maka diperoleh distribusi frekuensi skor yang dapat ditunjukkan pada tabel 8 di bawah ini:Tabel 4.7 Distribusi

Frekuensi dan Persentase Skor penerapan metode partisipatorik dalam meningkatkan hasil belajar bahasa Indonesia pada Siklus II

tinggi dan 4 siswa yang berada pada kategori sangat tinggi.

Apabila hasil belajar pada Siklus I dianalisis, maka persentase ketuntasan belajar siswa pada siklus I dapat dilihat pada Tabel 4.8 berikut:

Tabel 4.8 Deskripsi Ketuntasan Belajar Siswa Kelas XI SMA Negeri 19 Makassar pada Siklus II

\begin{tabular}{|c|c|c|c|}
\hline Skor & Kategori & Frekuensi & Persentase (\%) \\
\hline $0-64$ & Tidak tuntas & 0 & 0 \\
$65-100$ & Tuntas & 25 & 100 \\
\hline \multicolumn{2}{|c|}{ Jumlah } & 25 & 100 \\
\hline
\end{tabular}


Berdasarkan tabel 4.8 di atas bahwa siswa yang berada pada kategori tuntas sebanyak 25 siswa dengan persentase $100 \%$, sedangkan siswa yang berada pada kategori tidak tuntas sebanyak 0 siswa dengan persentase $0 \%$.

Berdasarkan hasil analisis kategori skor dipadukan dengan hasil observasi

dan diskusi dengan guru pembimbing atau kelas. Peneliti menarik kesimpulan bahwa pelaksanaan siklus II menunjukkan melalui metode partisipatorikmeningkat. Hasil yang diperoleh mengalami peningkatan.

\section{Kesimpulan dan Saran}

\section{Simpulan}

Berdasarkan hasil-hasil yang diperoleh dalam penelitian ini, dapat ditarik kesimpulan sebagai berikut:

Penerapan metode partisipatorik dalam meningkatkan hasil belajar bahasa Indonesia siswa kelasXI SMA Negeri 19 Makassar. Memahami berbagai informasi dari sambutan/khotbah dan wawancara dengan menggunakan metode partisipatorik dapat meningkatkan hasil belajar siswa kelas XI SMA Negeri 19 Makassar. Hal ini ditunjukkan dengan terjadinya peningkatan skor rata-rata hasil belajar dari siklus I kesiklus II yaitu 64,88 meningkat menjadi 82,28.

1. Terjadinya peningkatan pencapaian ketuntasan belajar dari siklus I kesiklus II yaitu $75 \%$ meningkat menjadi $100 \%$.

2. Terjadi perubahan aktivitas atau sikap siswa saat memahami pembacaan cerpen dengan menggunakan metode pembelajaran partisipatorik dalam pembelajaran yang dilihat kehadiran siswa dari siklus I 92,7\% meningkat pada siklus II $98,10 \%$,

3. Keaktifan dalam memperhatika nmateri yang dijelaska noleh guru dari siklus I 79,1\% meningkat pada siklus II 95,8\%, siswa yang mengajukkan pertanyaan dari siklus I $26,1 \%$ meningkat pada siklus II $38,6 \%$.

4. Pembelajaran memahami pembacaan cerpen dengan menggunakan metode partisipatorik sebahagian besar dari siswa yang menjadi subjek penelitian meresponnya secara positif pada siklus I 65,6\% meningkat pada siklus II $87,5 \%$.

\section{Saran}

1. Sebagai seorang guru, hendaknya harus mengetahui macam-macam metode mengajar dan mampu menyesuaikan metode-metode tersebut dengan topik-topik yang akan diajarkan sehingga dalam menyampaikan materi akan lebih bervariasi dan siswa tidak merasa bosan.

2. Diharapakan kepada para pengajar agar siswa dilibatkan dalam proses pembelajaran sehingga tercipta kemandirian dalam memecahkan masalah, sehingga pembelajaran memahami berbagai informasi dari sambutan/khotbah dan wawancara dengan menggunakan metode partisipatorik merupakan salah satu metode alternatif.

3. Diharapkan kepada para pengajar bidang studi bahasa Indonesia agar memberikan latihan yang cukup dan berulang, baik berupa soal-soal latihan yang dikerjakan di sekolah maupun dikerjakan di rumah dengan membuat soal secara bertahap mulai dari mudah ke yang sulit agar siswa lebih terlatih dan memiliki kepandaian dalam menyelesaikan soal-soal bahasa Indonesia.

4. Diharapkan kepada peneliti lain dalam bidang kependidikan khususnya pendidikan bahasa Indonesia dapat meneliti lebih lanjut tentang cara atau metode 
yang efektif dan efisien untuk mengatasi kesulitan siswa dalam mempelajari bahasa Indonesia.

5. Diharapkan kepada pemerintah agar memberikan kontribusi atau perhatian khusus kepada peneliti agar supaya pendidikan di Indonesia lebih meningkat.

\section{DAFTAR PUSTAKA}

Anita, Sri dkk. 2008. Strategi Pembelajaran. Jakarta. Universitas Terbuka.

Hasibuan, JJ., dkk. 1985. Proses Belajar Mengajar. Bandung: Rosdakarya.

Moeliono, Anton, dkk. 1990. Kamus Besar Bahasa Indonesia. Jakarta: Balai Pustaka.

Morris, William. 1976. The American Heritage Dictionary of the Engglish Language. Boston: Houghton Mifftin, Co.

Nurhadi. 2005. Membaca Cepat dan Efektif dan Pengajarannya. Surabaya. Usaha nasional.

Pidarta, M. 2005. Perencanaan Pendidikan Participatory dengan Pendekatan Sistem. Jakarta: Rineka Cipta.

Parwadarminta W.J.S. 1976. Kamus Umum Bahasa Indonesia. Jakarta: Balai Pustaka. 